\title{
Inhibition of return: Twenty years after
}

\author{
Juan Lupiáñez \\ Departamento de Psicologia Experimental y Fisiología del Comportamiento, University of Granada, Spain \\ Raymond M. Klein \\ Dalhousie University, Halifax, Nova Scotia, Canada \\ Paolo Bartolomeo \\ Inserm U 610 and Fédération de Neurologie, Hôpital de la Salpêtrière, Paris, France
}

\begin{abstract}
When responding to a suddenly appearing stimulus, we are slower and/or less accurate when the stimulus occurs at the same location of a previous event than when it appears in a new location. This phenomenon, often referred to as inhibition of return (IOR), has fostered a huge amount of research in the last 20 years. In this selective review, which introduces a Special Issue of Cognitive Neuropsychology dedicated to IOR, we discuss some of the methods used for eliciting IOR and its boundary conditions. We also address its debated relationships with orienting of attention, succinctly review findings of altered IOR in normal elderly and neuropsychiatric patients, and present results concerning its possible neural bases. We conclude with an outline of the papers collected in this issue, which offer a more in-depth treatment of behavioural, neural, and theoretical issues related to IOR.
\end{abstract}

Given the complexities of our interaction with the environment, the attentional system has evolved in humans to help the perceptual system to pick up the most relevant information, while ignoring less important information. In order to understand how information is selected from the environment it is important to know how attention operates, how it is oriented to the most relevant stimuli and events, whilst it is withdrawn from irrelevant information. Thus, attention in general and attentional orienting in particular has become one of the most important topics of research on cognitive psychology, cognitive neuropsychology, and cognitive neuroscience during the last decades, with much research being devoted to the study of the attentional mechanisms that modulate perception.

In this sense, it is nowadays well established that orienting can be performed in two different ways: an exogenous way, triggered bottom-up by external stimuli, and another more top-down, endogenous way, voluntarily triggered by the expectancies of the individual. This distinction between endogenous and exogenous spatial orienting is supported by a wealth of behavioural evidence in normal individuals (e.g., Funes, Lupiáñez, \& Milliken, 2005; Klein, 2004, for reviews) and brain-damaged patients (see Bartolomeo \& Chokron, 2002; Losier \& Klein, 2001), as well as by the existence of different

Correspondence should be addressed to Juan Lupiáñez, Departamento de Psicología, Universidad de Granada, 18011 Granada, Spain (Email: jlupiane@ugr.es) or to Paolo Bartolomeo, Inserm Unit 610, Pavillon Claude Bernard, Hôpital Salpêtrière, 47 bd de l'Hôpital, F-75013 Paris, France (Email: paolo.bartolomeo@chups.jussieu.fr). 
neural substrates (Corbetta \& Shulman, 2002, for a review; see also Kincade, Abrams, Astafiev, Shulman, \& Corbetta, 2005).

Much of this research has been influenced by the pioneer work of Michael Posner and colleagues who developed in the late seventies an experimental procedure, the cost and benefits paradigm (Posner, 1980; Posner, Nissen, \& Odgen, 1978), to study attention. This procedure has become so useful in the research of attention because it allows us to study, with simple manipulations, different modes of orienting and their boundary conditions and is simple enough as to be used not only with normal participants but also with different populations of patients and even in animals (Bartolomeo, Siéroff, Decaix, \& Chokron, 2001; Dorris, Klein, Everling, \& Munoz, 2002; Fuentes, Boucart, Vivas, Alvarez, \& Zimmerman, 2000; Posner, Rafal, Choate, \& Vaughan, 1985; Posner, Walker, Friedrich, \& Rafal, 1984).

Target stimuli are presented on a computer screen at one of two locations marked by one box each, one to the right and the other to the left of a central fixation point. A variable time before the target appears, a cue is presented to cue the target appearance at one of the two possible locations. Two different kinds of cue can be used with this procedure in order to study different types of attention. On the one hand, the cue can be presented at the centre and be predictive of target location with a probability above chance (e.g., a central arrow pointing either left or right). This way, the cue is to be interpreted, and participants have to develop an expectancy of target location according to the meaning of the cue. Attention can then be voluntarily oriented to the predicted location, leading to faster and/ or more accurate responses at this location than at the opposite location where attention is not oriented. This type of attentional orienting has been termed endogenous attention. On the other hand, the cue can be an increase in luminance in one of the peripheral boxes (e.g., the outline of the box is increased in size and/or luminance). By means of this type of cue, attention is automatically captured at the cued location without the cue having to be predictive at all. The abrupt onset of the cue in the periphery leads automatically to faster and/or more accurate responses at this location than at the opposite location, supposedly mediated by an involuntary shift of attention to the cued location.

Although these two types of attentional orienting lead to similar effects on performance, at least under some circumstances - that is, faster and/or more accurate responses (facilitation effects)there are important differences between the two modes of orienting (see Klein, 2004; Klein \& Shore, 2000, for reviews). One of the more important differences refers to the time course of exogenous versus endogenous orienting of attention, which has been studied by manipulating the asynchrony between the onset of the cue and the onset of the target (cue-target onset or stimulus onset asynchrony, CTOA or SOA). Exogenous cues lead to faster shifts of attention than do endogenous cues, as indexed by facilitation effects at the cued location (Müller \& Rabbitt, 1989). More importantly, the duration of the facilitation effect dramatically depends on the type of cue that is used. Whereas the effect of central symbolic cues remains positive (i.e., facilitation effect) for long intervals up to one second, the effect of peripheral nonpredictive cues is quite transient, so that it usually disappears after a few hundreds milliseconds.

Furthermore, and importantly for the present Special Issue, the facilitation effect observed with peripheral cues not only disappears after some time interval, but is reversed, so that after about $300 \mathrm{~ms}$ responses are now slower and/or less accurate at the location where the cue was presented than at the opposite location (see Klein, 2000, for a review). This phenomenon was discovered independently in the 1980s by the Posner group (Posner \& Cohen, 1984) in the US and by the Berlucchi group (Tassinari, Aglioti, Chelazzi, Marzi, \& Berlucchi, 1987) in Italy, and it has since inspired an impressive and ever-increasing number of studies in the cognitive neuroscience community. The effect has received different names such as "inhibitory aftereffect" (Tassinari et al., 1987) or "inhibitory tagging" 
(Fuentes, Vivas, \& Humphreys, 1999; Klein, 1988). However, Posner, Rafal, and colleagues (Posner et al., 1985) termed this phenomenon "inhibition of return" (IOR), and this is the name that is used most often in the cognitive neuroscience and experimental psychology laboratories.

Since the discovery of the phenomenon, IOR has lead to an important amount of research in cognitive neuroscience, having a big impact in the field of attention, as the effect has been used to study different issues on attention and spatial cognition and attentional deficits in different clinical and subclinical populations and brain-damaged patients. To get an idea of the impact that the phenomenon has had in the field, we should note that the original paper by Posner and Cohen (1984) has been cited more than 800 times in journals of the Science Citation Index (ISI Web of Science. Thomson ISI. Philadelphia, PA, USA). The paper by Posner et al. (1985) has been cited nearly 300 times (122 times in the last 5 years from 2000 to 2004). See Table 1 for the 20 most cited papers on IOR in journals of the ISI web of knowledge. More importantly, as can be observed in Figure 1, more than 300 papers have been published on IOR since its discovery in 1984, with around 40 papers per year being published during the last years.

\section{IOR: Methods, findings, and theories}

The model task pioneered by Posner for exploring covert orienting, as described above, has provided the methodological foundation for most studies of IOR. An uninformative peripheral cue is presented at one of two locations followed after various delays by a target at the cued or uncued location. In the earliest studies the target called for a simple detection response, and catch trials were used to discourage anticipatory responding. At short intervals performance is usually better at the cued location, an advantage attributed to attentional capture by the cue. In Posner and Cohen's (1984) implementation of this task, two different methods were used to ensure that when testing at longer intervals, attention would not simply remain at the cued location: Either a second cue was presented at fixation after the peripheral cue; or targets were presented at fixation with a higher probability than that of either peripheral location. The former method would return attention exogenously to fixation (a neutral state with regard to the potential targets) while, with the latter method, it is reasonable to assume that the participant would do this endogenously. Many studies have successfully elicited IOR in normal adults using neither of these methods, suggesting that the equal probability of receiving a target at the possible target locations provides sufficient incentive for these participants to place their attention in a neutral state some time after the cue. In participants with poor volitional control of attention (e.g., children, schizophrenics, the elderly), however, the endogenous removal of attention from the cue may be sluggish, and therefore the appearance of IOR may be significantly delayed, or even absent, if measures are not taken to exogenously return attention to fixation after it is captured by the peripheral cue (for a review, see Klein, 2005).

The timecourse and spatial distribution of IOR has been explored by varying the time and distance between the cue and target. These studies have shown that IOR is relatively long lasting (persisting for up to 3 seconds in some studies, see Samuel \& Kat, 2003, for a review) and that there is a gradient of inhibition around the originally cued location (Bennett \& Pratt, 2001; Dorris, Taylor, Klein, \& Munoz, 1999; Maylor \& Hockey, 1985). When a return cue at fixation is not used, the time when facilitation at the cued location is replaced by inhibition may be delayed when the difficulty of the target task is increased (Lupiáñez, Milan, Tornay, Madrid, \& Tudela, 1997) and when a verbal memory load interferes with the endogenous return of attention from the cued location (Klein, Castel, \& Pratt, in press). When the participant is given reason to attend to a location endogenously, whether through instruction without a probability manipulation (Berlucchi, Chelazzi, \& Tassinari, 2000) or because targets are likely to occur there 
LUPIÁÑEZ, KLEIN, BARTOLOMEO

Table 1. List of the 20 most highly cited papers on inbibition of return

\begin{tabular}{|c|c|c|c|}
\hline Authors & Title & Year & No. of times cited \\
\hline Posner \& Cohen & Components of visual orienting & 1984 & 835 \\
\hline Posner, Rafal, Choate, \& Vaughan & $\begin{array}{l}\text { Inhibition of return: Neural basis and } \\
\text { function }\end{array}$ & 1985 & 285 \\
\hline Rafal, Calabresi, Brennan, \& Sciolto & $\begin{array}{l}\text { Saccade preparation inhibits reorienting to } \\
\text { recently attended locations }\end{array}$ & 1989 & 258 \\
\hline Maylor & $\begin{array}{l}\text { Facilitatory and inhibitory components of } \\
\text { orienting in visual space }\end{array}$ & 1985 & 237 \\
\hline Houghton \& Tipper & $\begin{array}{l}\text { A model of inhibitory mechanisms in } \\
\text { selective attention }\end{array}$ & 1994 & 203 \\
\hline Maylor \& Hockey & $\begin{array}{l}\text { Inhibitory component of externally } \\
\text { controlled covert orienting in visual space }\end{array}$ & 1985 & 174 \\
\hline Klein & Inhibition of return & 2000 & 173 \\
\hline Tipper, Driver, \& Weaver & $\begin{array}{l}\text { Object-centered inhibition of return of } \\
\text { visual-attention }\end{array}$ & 1991 & 160 \\
\hline Klein & $\begin{array}{l}\text { Inhibitory tagging system facilitates } \\
\text { visual-search }\end{array}$ & 1988 & 158 \\
\hline Tipper, Weaver, Jerreat, \& Burak & $\begin{array}{l}\text { Object-based and environment-based } \\
\text { inhibition of return of visual-attention }\end{array}$ & 1994 & 138 \\
\hline Abrams \& Dobkin & $\begin{array}{l}\text { Inhibition of return: Effects of attentional } \\
\text { cueing on eye-movement latencies }\end{array}$ & 1994 & 132 \\
\hline Klein \& Taylor & $\begin{array}{l}\text { Categories of cognitive inhibition with } \\
\text { reference to attention }\end{array}$ & 1994 & 121 \\
\hline Connelly \& Hasher & Aging and the inhibition of spatial location & 1993 & 113 \\
\hline $\begin{array}{l}\text { Tassinari, Aglioti, Chelazzi, } \\
\text { Marzi, \& Berlucchi }\end{array}$ & $\begin{array}{l}\text { Distribution in the visual-field of the costs of } \\
\text { voluntarily allocated attention and of the } \\
\text { inhibitory aftereffects of covert orienting }\end{array}$ & 1987 & 111 \\
\hline Rafal \& Henik & $\begin{array}{l}\text { The neurology of inhibition: Integrating } \\
\text { controlled and automatic processes }\end{array}$ & 1994 & 109 \\
\hline $\begin{array}{l}\text { Lupiáñez, Milan, Tornay, } \\
\text { Madrid, \& Tudela }\end{array}$ & $\begin{array}{l}\text { Does IOR occur in discrimination tasks? Yes, } \\
\text { it does, but later }\end{array}$ & 1997 & 92 \\
\hline Taylor \& Klein & $\begin{array}{l}\text { On the causes and effects of inhibition of } \\
\text { return }\end{array}$ & 1998 & 91 \\
\hline Reuter-Lorenz, Jha, \& Rosenquist & What is inhibited in inhibition of return? & 1996 & 89 \\
\hline Klein \& MacInnes & $\begin{array}{l}\text { Inhibition of return is a foraging facilitator in } \\
\text { visual search }\end{array}$ & 1999 & 86 \\
\hline Gibson \& Egeth & $\begin{array}{l}\text { Inhibition of return to object-based and } \\
\text { environment-based locations }\end{array}$ & 1994 & 70 \\
\hline
\end{tabular}

(Chica, Lupiáñez, \& Bartolomeo, 2006; Lupiáñez, Decaix, Siéroff, Chokron, Milliken, \& Bartolomeo, 2004), IOR is observed at the endogenously attended location. This finding has been used to argue against the assertion that IOR is the result of the inhibition of the return of attention to the originally cued and attended location and hence against the very label "inhibition of return" (Berlucchi, 2006). Another possibility is that there are in fact two "beams" of attention: the one controlled "top-down" or endogenously, usually in the absence of asymmetric visual stimulation, and the one controlled exogenously by virtue the "bottom-up" salience of array elements (Briand \& Klein, 1987; Klein, 1994; Klein \& Shore, 2000). By operating on the salience map, IOR may delay exogenous orienting based on bottom-up signals without affecting endogenous orienting. Converging evidence for this view comes from the finding that IOR follows exogenously but not endogenously generated shifts of attention (Posner \& Cohen, 1984; 


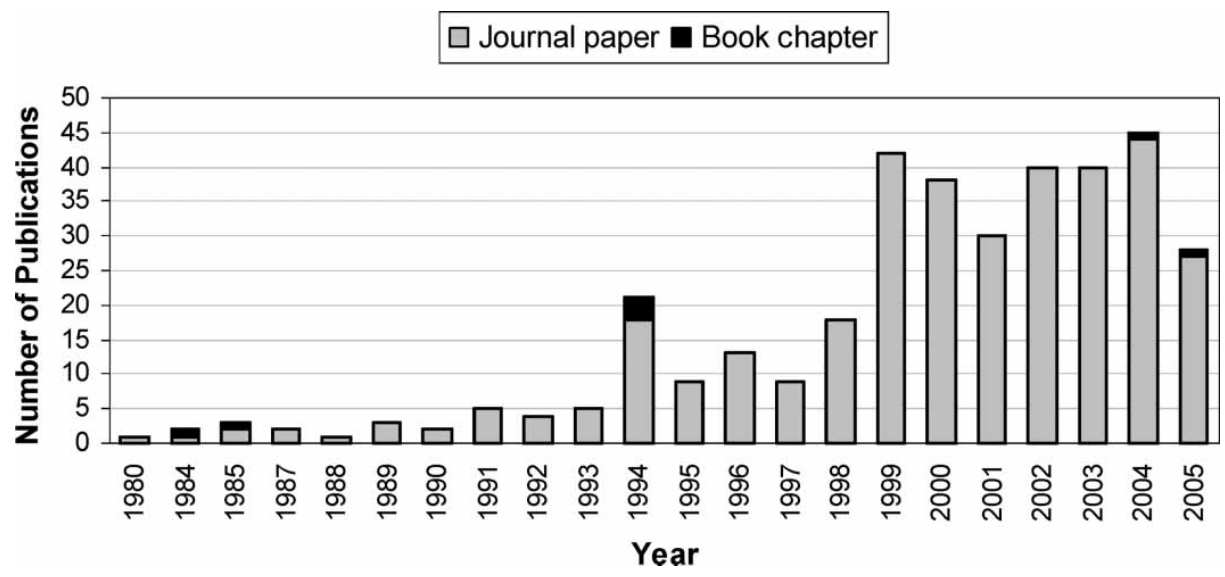

Figure 1. Number of papers on IOR (with this or other names) published per year.

Rafal, Calabresi, Brennan, \& Sciolto, 1989). According to this view, from the perspective of both cause and effect, endogenous orienting might be independent of IOR.

Interposing a saccade between the cue and target, Posner and Cohen (1984) and Maylor and Hockey (1985) found that it was not the retinal location of the cue that was inhibited, but rather the location of the cue in the environment. Similarly, interposing motion of the array elements between a cue and target, Tipper, Driver, and Weaver (1991) found that targets presented on the originally stimulated object were inhibited, even when that object had moved to the location where the uncued object had been at the time of the cue. These studies show that, when necessitated by ocular or object movements, IOR can be coded in an environmental or object frame of reference. Suggesting that IOR may be encoded in a multimodal structure, IOR has also been obtained in touch and audition, and between all cue-target pairings of vision, touch, and audition (Spence, Lloyd, McGlone, Nicholls, \& Driver, 2000). All these findings place the cause of IOR at some distance from the early sensory pathway stimulated by the cue.

When entertaining assertions about the perceptual, attentional, and motoric nature of IOR it is necessary to consider whether these assertions are about what causes IOR or, once
IOR has been caused, what kinds of information processing are affected by the hypothetical inhibition (Taylor \& Klein, 1998). Rafal et al. (1989) used central arrows or peripheral cues to induce their participants to generate overt orienting (a saccade), covert orienting (a shift of attention) or to prepare a saccade. After an endogenously or exogenously elicited saccade, the eyes returned to fixation, and, reflecting IOR, a target calling for a detection response was responded to slower when presented at the previously fixated location. On a proportion of trials calling for a shift of attention or preparation of a saccade, a stimulus at fixation informed the participant to cancel the shift or cease the preparation. The cancellation of saccadic preparation caused IOR whether an endogenous or exogenous cue had been used to generate the preparation. Finally, replicating Posner and Cohen (1984), IOR was found after an exogenous but not after an endogenous shift of attention. Because the conditions that elicited IOR in this study have in common an oculomotor programme (either executed or activated), oculomotor programming is strongly implicated as playing a critical role in causing IOR.

Once caused does IOR affect perceptual, attentional, or motor processing? When a choice task is used, IOR interacts with the Simon effect (Ivanoff, Klein, \& Lupiáñez, 2002), and when a detection 
response is used IOR doubles when the nonresponding hand is placed on the keyboard (Ivanoff \& Klein, 2001). These findings implicate an effect at the level of motor processing. The effect seems to be related to a bias to avoid responses to targets at a previously cued location (Ivanoff \& Klein, 2001) rather than inhibition of such responses (Prime \& Ward, 2004). On the one hand, as indexed by temporal order judgements (Klein, Schmidt, \& Muller, 1998) and illusory line motion (Schmidt, 1996) perceptual arrival times do not seem to be affected by IOR. On the other hand, perceptual sensitivity $\left(d^{\prime}\right)$ is reduced at a previously cued location both with masked targets (Handy, Jha, \& Mangun, 1999) and as a function of response speed using a deadline procedure (Ivanoff \& Klein, in press). Taken together these findings suggest that IOR may operate at several stages of processing to discourage orienting toward previously cued locations. Two "flavours" of IOR were reported by Taylor and Klein (2000) using central arrows and peripheral events as the first or second of two successive stimuli. When the oculomotor system was engaged (by either the first or the second stimulus) the inhibition laid down by the first stimulus had a motoric effect (responses in the same direction as that indicated by the first stimulus were retarded even when the second stimulus was a central arrow). In contrast, when the oculomotor system was quiescent (manual responses were made to the second stimulus after the first one was ignored, or responded to manually) the effect was upon attention/perception: Inhibition was only observed in response to peripheral events. A similar dissociation has been reported by Sumner and coworkers (Sumner, 2006; Sumner, Nachev, Vora, Husain, \& Kennard, 2004). Following typical stimuli they found IOR for manual and saccadic targets, while for cues that were invisible to the superior colliculus, IOR was observed for manual but not saccadic responses. Unlike Taylor and Klein's dissociation, which is about the effect(s) of IOR, Sumner's is about the generation of IOR: When IOR is generated by stimuli that bypass the superior colliculus the inhibition does not affect reflexive saccades.
Posner and Cohen (1984) speculated that IOR might serve to encourage orienting toward novel objects and events. Extending this suggestion, Klein (1988) proposed that IOR might operate in visual search to discourage wasteful reinspections. Using a probe-after-search procedure, he confirmed this proposal by finding IOR at the locations of distractors during difficult, but not easy (popout), visual search (see also Takeda \& Yagi, 2000). Klein and MacInnes (1999) extended this finding to oculomotor search of complex scenes (from Martin Handford's "Where's Waldo" books). When probe targets interrupted search or when they were presented after the participant had temporarily ceased searching (Macinnes \& Klein, 2003) the time to foveate the probe declined as the distance of the probe from a recently fixated region of the scene increased. When observers are free to search a scene for a target, a tendency to avoid reinspections could be due to a passive inhibitory tagging system like IOR or to the adoption of a deliberate strategy to scan the array in a particular order. This ambiguity was eliminated by McCarley, Wang, Kramer, Irwin, and Peterson (2003) using a task in which the experimenter guides oculomotor behaviour by presenting a sequence of targets. Here there is no possibility of the observer planning the scanpath for inspecting objects in a scene because the experimenter is presenting items one at a time. When the observer is given a choice between targets, with one presented at a new location and one presented at an old location, there is a strong bias to inspect the target at the new location (McCarley et al., 2003). This bias, reflecting IOR, is so strong that observers find it difficult to follow an instruction to select the old object when it is presented with a new one (Boot, McCarley, Kramer, \& Peterson, 2004).

\section{IOR and cognitive neuroscience}

Inhibition of return has been used to study different issues in cognitive neuroscience, more specifically in the fields of attention and spatial cognition, as a tool to study both the underlying mechanisms and the neural structures on which 
they are subtended. Thus, IOR has been used to study the development of the attentional orienting mechanism from the first days after birth (i.e., in newborns) to the late stages of decline in the elderly, to study attention on patients with psychological and psychiatric disorders and on neuropsychological patients, and to search the brain for areas involved in attention. As discussed above, IOR has been used to investigate the frames of reference on which attention can act and whether attention is unimodal versus crossmodal, and not only to study attention but to investigate how attention modulates and can be subserved by other processes such as perception and memory.

IOR has been used to study the development of the visual and attentional system in infants from the early newborn stages until the decline with age in the elderly. Thus, newborns show IOR from the first day after birth (Valenza, Simion, \& Umiltà, 1994). Nevertheless, it was shown that the eccentricity at which infants show IOR varies with age, in close relation with the eccentricity at which they can make accurate saccades (Harman, Posner, Rothbart, \& Thomas-Thrapp, 1994), which suggest that IOR can be taken as an index of the maturation of the eye-movement system. Studies which included a longer range of ages showed that the IOR effect observed in children and adolescents from around 1 up to 17 years old varies and depends on the cue-target SOA that is used and the presence versus absence of a central reorienting cue (MacPherson, Klein, \& Moore, 2003; Richards, 2000).

Moving now to the late decline with age, IOR has also been used to study attentional dynamics in the elderly and in patients with Alzheimer's disease. Although previous studies showed no differences in IOR between young and older adults (Hartley \& Kieley, 1995), when the time course is taken into account elderly people have shown IOR at later cue-target intervals (Castel, Chasteen, Scialfa, \& Pratt, 2003). Similarly, they have shown a deficit when object-based IOR is measured, but not when location-based IOR is measured (McCrae \& Abrams, 2001). In the same guise, several studies have shown relatively normal IOR in patients with Alzheimer's disease
(Danckert, Maruff, Crowe, \& Currie, 1998; Faust \& Balota, 1997; Langley, Fuentes, Hochhalter, Brandt, \& Overmier, 2001; for a review, see Amieva, Phillips, Della Sala, \& Henry, 2004). However, when some parameters of the procedure such as the task (Langley et al., 2001), time course (Langley et al., 2001), or the presence versus absence of a central reorienting cue (Faust \& Balota, 1997) were studied, Alzheimer's disease patients did show some deficits of IOR. Similarly, a reduction or elimination of IOR has been documented in patients with Parkinson's disease (Poliakoff, O’Boyle, Moore, McGlone, Cody, \& Spence, 2003).

Several psychological and psychiatric populations have been shown to have attentional deficits as revealed by abnormal patterns of IOR. Thus, patients with obsessive-compulsive disorder have been observed to show reduced IOR (Nelson, Early, \& Haller, 1993; Rankins, Bradshaw, Moss, \& Georgiou-Karistianis, 2004), with perhaps this mechanism explaining their difficulties in disengaging from actions, whereas deaf subjects can disengage their attention faster than can hearing subjects, as indexed by a faster decay of IOR (Colmenero, Catena, Fuentes, \& Ramos, 2004). Regarding attention deficit hyperactivity disorder, it is not clear whether these subjects have really an impairment in the attentional mechanism subserving IOR, as they only show a slightly smaller IOR effect than do controls (Li, Chang, \& Lin, 2003). Children and adolescents with spina bifida meningomyelocele show attenuated IOR in the vertical plane (Dennis et al., 2005), which is taken as evidence for their problems in orienting to salient stimuli.

Schizophrenic patients have been reported to show abnormal IOR depending on the type of patient and the specific procedure that was used to measure the IOR effect. Thus, Huey and Wexler (1994) showed smaller and delayed IOR on medicated and clinically stable schizophrenic outpatients than on healthy control participants. Similarly, Gouzoulis-Mayfrank, Heekeren, Voss, Moerth, Thelen, and Meincke (2004) reported blunted IOR, and Larrison-Faucher, Briand, and Sereno (2002) reported delayed onset in 
schizophrenic patients, as compared to control participants. However, Fuentes and colleagues have reported normal levels of IOR on medicated schizophrenic patients (Fuentes, Boucart, Alvarez, Vivas, \& Zimmerman, 1999; Fuentes \& Santiago, 1999), and Sapir, Henik, Dobrusin, and Hochman (2001) reported IOR as being present or not on medicated patients depending on whether a central reorienting cue was presented at fixation. Important parameters of the procedure that is used to measure IOR, such as the duration of the cue, the SOA and the presentation of a reorienting cue at fixation, could explain the different results observed in the different studies.

Damage to the central nervous system may or not influence IOR. Patients with damage to the pulvinar nucleus of the thalamus have been reported to show normal IOR (Danziger, Ward, Owen, \& Rafal, 2001; Sapir, Rafal, \& Henik, 2002). Similarly, Danziger, Fendrich, and Rafal (1997) reported normal IOR in hemianopic patients, even when the cues were presented in the blind field. However, patients with conversion paresis seem to show blunted or no IOR (Roelofs, van Galen, Eling, Keijsers, \& Hoogduin, 2003), whereas patients with parietal damage with or without spatial neglect seem to show quite unaltered IOR at the contralesional side, in contrast to reduced IOR, a lack of effect or even facilitation (instead of IOR) at the ipsilesional side (Bartolomeo, Chokron, \& Siéroff, 1999; Bartolomeo et al., 2001; Lupiáñez et al., 2004; Sapir, Hayes, Henik, Danziger, \& Rafal, 2004; Vivas, Humphreys, \& Fuentes, 2003).

Sapir, Soroker, Berger, and Henik (1999) reported a lack of IOR in a patient with damage to the superior colliculus (no IOR only in the visual fields projecting to the damaged right $\mathrm{SC}$, i.e., the left temporal hemifield and the nasal right hemifield). On the other hand, Tipper, Rafal, and colleagues (Tipper et al., 1997) reported that object-based IOR could be observed in two split-brain patients, provided that the cued object remained in the same hemifield; as soon as it crossed the midfield IOR disappeared (in fact, it reversed to facilitation). These two studies clearly show that, although the superior colliculus seems to be an important structure related to IOR, cortical structures are also involved. Depending perhaps on the frames of reference on which attention is acting, and therefore in which IOR is being measured, different neural cortical and subcortical structures might be involved in the generation of IOR.

\section{Outline of the special issue}

The papers collected in this Special Issue largely result from a session of the 23rd European Workshop on Cognitive Neuropsychology, Bressanone, Italy, organized in 2005 by the guest editors of this issue, in the 20th anniversary of the publication of the IOR eponymous paper in Cognitive Neuropsychology (Posner et al., 1985).

The first article is devoted to the behavioural exploration of IOR. Chica et al. (2006) replicated the demonstration that IOR can occur at endogenous attended locations and extended this finding to both detection and discrimination tasks. These results cast doubts on the traditional account of IOR as resulting from the inhibition of the return of attention to a previously inspected location, at least as far as endogenous attention is concerned.

Petroc Sumner's contribution (Sumner, 2006) focuses on the neural bases of IOR. Sumner developed an elegant paradigm for identifying collicular contributions to visual orienting. Either standard luminance cues or S-cone cues, which are invisible to the direct collicular pathways, are presented. The results show that there are (at least) two types of IOR: one affecting both manual and ocular responses, presumably depending on the superior colliculus, and the other affecting only manual responses, presumably depending on the cortex. This study indicates directions for a possible taxonomy of distinct types of IOR.

If $\mathrm{IOR}$ requires, at least in part, cortical processes, then it should be impaired in brain-damaged patients. Vivas, Humphreys, and Fuentes (2006) show that this is actually the case. Patients with parietal lesions had decreased IOR for stimuli occurring on the same side as 
their brain lesion, perhaps as a consequence of an imbalance of the relative salience of signals.

In the last paper, Giovanni Berlucchi (2006), one of the discoverers of the phenomenon, further stresses the difficulties of interpreting IOR as a mere bias against returning to a previously explored location. Consequently, the very name of inhibition of return might be inappropriate. Berlucchi makes the intriguing suggestion that these after-effects might actually result from two processes; a first, sensory effect would determine a consequent orienting effect. In other words, sensory attenuation immediately following a peripherally presented stimulus might produce a subsequent deficit of (exogenous) orienting towards stimuli occurring in the same location.

We hope that this collection of papers will provide the reader with a state-of-the-art knowledge of inhibitory after-effects in spatial processing and with a flavour of the exciting perspectives that these phenomena open for the cognitive neuroscience community.

First published online 6 July 2006

\section{REFERENCES}

Abrams, R. A., \& Dobkin, R. S. (1994). Inhibition of return: Effects of attentional cuing on eye movement latencies. Journal of Experimental Psychology: Human Perception and Performance, 20, 467-477.

Amieva, H., Phillips, L. H., Della Sala, S., \& Henry, J. D. (2004). Inhibitory functioning in Alzheimer's disease. Brain, 127, 949-964.

Bartolomeo, P., \& Chokron, S. (2002). Orienting of attention in left unilateral neglect. Neuroscience and Biobehavioral Reviews, 26, 217-234.

Bartolomeo, P., Chokron, S., \& Siéroff, E. (1999). Facilitation instead of inhibition for repeated right-sided events in left neglect. NeuroReport, 10, 3353-3357.

Bartolomeo, P., Siéroff, E., Decaix, C., \& Chokron, S. (2001). Modulating the attentional bias in unilateral neglect: The effects of the strategic set. Experimental Brain Research, 137, 424-431.

Bennett, P. J., \& Pratt, J. (2001). The spatial distribution of inhibition of return. Psychological Science, $12,76-80$.
Berlucchi, G. (2006). Inhibition of return: A phenomenon in search of a mechanism and a better name. Cognitive Neuropsychology, 23, 1065-1074.

Berlucchi, G., Chelazzi, L., \& Tassinari, G. (2000). Volitional covert orienting to a peripheral cue does not suppress cue-induced inhibition of return. Journal of Cognitive Neuroscience, 12, 648-663.

Boot, W. R., McCarley, J. S., Kramer, A. F., \& Peterson, M. S. (2004). Automatic and intentional memory processes in visual search. Psychonomic Bulletin E Review, 11, 854-861.

Briand, K. A., \& Klein, R. M. (1987). Is Posner's "beam" the same as Treisman's "glue"?: On the relation between visual orienting and feature integration theory. Journal of Experimental Psychology: Human Perception and Performance, 13, 228-241.

Castel, A. D., Chasteen, A. L., Scialfa, C. T., \& Pratt, J. (2003). Adult age differences in the time course of inhibition of return. Journals of Gerontology B: Psychological Sciences and Social Sciences, 58, 256-259.

Chica, A. B., Lupiáñez, J., \& Bartolomeo, P. (2006). Dissociating IOR from endogenous orienting of spatial attention: Evidence from detection and discrimination tasks. Cognitive Neuropsychology, 23, 1015-1034.

Colmenero, J. M., Catena, A., Fuentes, L. J., \& Ramos, M. M. (2004). Mechanisms of visuospatial orienting in deafness. European Journal of Cognitive Psychology, 16, 791-805.

Connelly, S. L., \& Hasher, L. (1993). Aging and the inhibition of spatial location. Journal of Experimental Psychology: Human Perception and Performance, 19, 1238-1250.

Corbetta, M., \& Shulman, G. L. (2002). Control of goal-directed and stimulus-driven attention in the brain. Nature Reviews Neuroscience, 3, 201-215.

Danckert, J., Maruff, P., Crowe, S., \& Currie, J. (1998). Inhibitory processes in covert orienting in patients with Alzheimer's disease. Neuropsychology, 12, 225-241.

Danziger, S., Fendrich, R., \& Rafal, R. D. (1997). Inhibitory tagging of locations in the blind field of hemianopic patients. Consciousness and Cognition, 6, 291-307.

Danziger, S., Ward, R., Owen, V., \& Rafal, R. (2001). The effects of unilateral pulvinar damage in humans on reflexive orienting and filtering of irrelevant information. Behavioural Neurology, 13, 95-104.

Dennis, M., Edelstein, K., Copeland, K., Frederick, J. A., Francis, D. J., Hetherington, R., et al. (2005). Spacebased inhibition of return in children with spina bifida. Neuropsychology, 19, 456-465. 
Dorris, M. C., Klein, R. M., Everling, S., \& Munoz, D. P. (2002). Contribution of the primate superior colliculus to inhibition of return. Journal of Cognitive Neuroscience, 14, 1256-1263.

Dorris, M. C., Taylor, T. L., Klein, R. M., \&Munoz, D. P. (1999). Influence of previous visual stimulus or saccade on saccadic reaction times in monkey. Journal of Neurophysiology, 81, 2429-2436.

Faust, M. E., \& Balota, D. A. (1997). Inhibition of return and visuospatial attention in healthy older adults and individuals with dementia of the Alzheimer type. Neuropsychology, 11, 13-29.

Fuentes, L. J., Boucart, M., Alvarez, R., Vivas, A. B., \& Zimmerman, M. A. (1999). Inhibitory processing in visuospatial attention in healthy adults and schizophrenic patients. Schizophrenia Research, 40, 75-80.

Fuentes, L. J., Boucart, M., Vivas, A. B., Alvarez, R., \& Zimmerman, M. A. (2000). Inhibitory tagging in inhibition of return is affected in schizophrenia: Evidence from the Stroop task. Neuropsychology, 14, 134-140.

Fuentes, L. J., \& Santiago, E. (1999). Spatial and semantic inhibitory processing in schizophrenia. Neuropsychology, 13, 259-270.

Fuentes, L. J., Vivas, A. B., \& Humphreys, G. W. (1999). Inhibitory tagging of stimulus properties in inhibition of return: Effects on semantic priming and flanker interference. Quarterly Journal of Experimental Psychology, 52A, 149-164.

Funes, M. J., Lupiáñez, J., \& Milliken, B. (2005). The role of spatial attention and other processes on the magnitude and time course of cueing effects. Cognitive Processing, 6, 98-116.

Gibson, B. S., \& Egeth, H. (1994). Inhibition of return to object-based and environment-based locations. Perception \& Psychophysics, 55, 323-339.

Gouzoulis-Mayfrank, E., Heekeren, K., Voss, T., Moerth, D., Thelen, B., \& Meincke, U. (2004). Blunted inhibition of return in schizophreniaevidence from a longitudinal study. Progress in Neuropsychopharmacology \& Biological Psychiatry, 28, 389-396.

Handy, T. C., Jha, A. P., \& Mangun, G. R. (1999). Promoting novelty in vision: Inhibition of return modulates perceptual-level processing. Psychological Science, 10, 157-161.

Harman, C., Posner, M. I., Rothbart, M. K., \& Thomas-Thrapp, L. (1994). Development of orienting to locations and objects in human infants. Shifts of visual attention [Special issue]. Canadian Journal of Experimental Psychology, 48, 301-318.
Hartley, A. A., \& Kieley, J. M. (1995). Adult age differences in the inhibition of return of visual attention. Psychology and Aging, 10, 670-683.

Houghton, G., \& Tipper, S. P. (1994). A model of inhibitory mechanisms in selective attention. In D. Dagenbach \& T. H. Carr (Eds.), Inbibitory processes in attention, memory, and language (pp. 53-112). San Diego, CA: Academic Press.

Huey, E. D., \& Wexler, B. E. (1994). Abnormalities in rapid, automatic aspects of attention in schizophrenia: Blunted inhibition of return. Schizophrenia Research, 14, 57-63.

Ivanoff, J., \& Klein, R. M. (2001). The presence of a nonresponding effector increases inhibition of return. Psychonomic Bulletin E Review, 8, 307-314.

Ivanoff, J., \& Klein, R. M. (in press). A speed-accuracy analysis of inhibition of return in go/no-go and choice-RT tasks. Journal of Experimental Psychology: Human Perception and Performance.

Ivanoff, J., Klein, R. M., \& Lupiáñez, J. (2002). Inhibition of return interacts with the Simon effect: An omnibus analysis and its implications. Perception E Psychophysics, 64, 318-327.

Kincade, J. M., Abrams, R. A., Astafiev, S. V., Shulman, G. L., \& Corbetta, M. (2005). An event-related functional magnetic resonance imaging study of voluntary and stimulus-driven orienting of attention. Journal of Neuroscience, 25, 4593-4604.

Klein, R. M. (1988). Inhibitory tagging system facilitates visual search. Nature, 334, 430-431.

Klein, R. M. (1994). Perceptual-motor expectancies interact with covert visual orienting under conditions of endogenous but not exogenous control. Canadian Journal of Experimental Psychology, 48, 167-181.

Klein, R. M. (2000). Inhibition of return. Trends in Cognitive Sciences, 4, 138-147.

Klein, R. M. (2004). On the control of visual orienting. In M. I. Posner (Ed.), Cognitive neuroscience of attention (pp. 29-44). New York: Guilford Press.

Klein, R. M. (2005). On the role of endogenous orienting in the inhibitory aftermath of exogenous orienting. In U. Mayr, E. Awh, \& S. Keele (Eds.), Developing individuality in the human brain: A feschrift for Michael Posner (pp. 45-64). Washington, DC: APA Books.

Klein, R. M., Castel, A., \& Pratt, J. (in press). The effects of memory load on the timecourse of inhibition of return. Psychonomic Bulletin $\mathcal{E}$ Review.

Klein, R. M., \& MacInnes, W. J. (1999). Inhibition of return is a foraging facilitator in visual search. Psychological Science, 10, 346-352. 
Klein, R. M., Schmidt, W. C., \& Muller, H. J. (1998). Disinhibition of return: Unnecessary and unlikely. Perception E Psychophysics, 60, 862-872.

Klein, R. M., \& Shore, D. I. (2000). Relations among modes of visual orienting. In S. Monsell \& J. Driver (Eds.), Attention \& performance XVIII: Control of cognitive processes (pp. 195-208). Cambridge, MA: MIT Press.

Klein, R. M., \& Taylor, T. L. (1994). Categories of cognitive inhibition with reference to attention. In D. Dagenbach \& T. H. Carr (Eds.), Inbibitory processes in attention, memory, and language (pp. 113-150). San Diego, CA: Academic Press.

Langley, L. K., Fuentes, L. J., Hochhalter, A. K., Brandt, J., \& Overmier, J. B. (2001). Inhibition of return in aging and Alzheimer's disease: Performance as a function of task demands and stimulus timing. Journal of Clinical and Experimental Neuropsychology, 23, 431-446.

Larrison-Faucher, A., Briand, K. A., \& Sereno, A. B. (2002). Delayed onset of inhibition of return in schizophrenia. Progress in Neuropsychopharmacology $\varepsilon^{\circ}$ Biological Psychiatry, 26, 505-512.

Li, C. S., Chang, H. L., \& Lin, S. C. (2003). Inhibition of return in children with attention deficit hyperactivity disorder. Experimental Brain Research, 149, 125-130.

Losier, B. J., \& Klein, R. M. (2001). A review of the evidence for a disengage deficit following parietal lobe damage. Neuroscience and Biobehavioral Reviews, 25, $1-13$.

Lupiáñez, J., Decaix, C., Siéroff, E., Chokron, S., Milliken, B., \& Bartolomeo, P. (2004). Independent effects of endogenous and exogenous spatial cueing: Inhibition of return at endogenously attended target locations. Experimental Brain Research, 159, 447-457.

Lupiáñez, J., Milan, E. G., Tornay, F. J., Madrid, E., \& Tudela, P. (1997). Does IOR occur in discrimination tasks? Yes, it does, but later. Perception and Psychophysics, 59, 1241-1254.

Macinnes, J. W., \& Klein, R. M. (2003). Inhibition of return biases orienting during the search of complex scenes. Scientific World Journal, 3, 75-86.

MacPherson, A. C., Klein, R. M., \& Moore, C. (2003). Inhibition of return in children and adolescents. Journal of Experimental Child Psychology, 85(4), 337-351.

Maylor, E. A. (1985). Facilitatory and inhibitory components of orienting in visual space. In M. I. Posner \& O. S. Marin (Eds.), Attention and performance XI (pp. 189-204). Hillsdale, NJ: Lawrence Erlbaum Associates, Inc.

Maylor, E. A., \& Hockey, R. (1985). Inhibitory component of externally controlled covert orienting in visual space. Journal of Experimental Psychology: Human Perception and Performance, 11, 777-787.

McCarley, J. S., Wang, R. F., Kramer, A. F., Irwin, D. E., \& Peterson, M. S. (2003). How much memory does oculomotor search have? Psychological Science, 14, 422-426.

McCrae, C. S., \& Abrams, R. A. (2001). Age-related differences in object- and location-based inhibition of return of attention. Psychology and Aging, 16, 437-449.

Müller, H. J., \& Rabbitt, P. M. (1989). Reflexive and voluntary orienting of visual attention: time course of activation and resistance to interruption. Journal of Experimental Psychology: Human Perception and Performance, 15, 315-330.

Nelson, E., Early, T. S., \& Haller, J. W. (1993). Visual attention in obsessive-compulsive disorder. Psychiatry Research, 49, 183-196.

Poliakoff, E., O’Boyle, D. J., Moore, A. P., McGlone, F. P., Cody, F. W., \& Spence, C. (2003). Orienting of attention and Parkinson's disease: Tactile inhibition of return and response inhibition. Brain, 126, 2081-2092.

Posner, M. I. (1980). Orienting of attention. Quarterly Journal of Experimental Psychology, 32, 3-25.

Posner, M. I., \& Cohen, Y. (1984). Components of visual orienting. In H. Bouma \& D. Bouwhuis (Eds.), Attention and performance X (pp. 531-556). Hove, UK: Lawrence Erlbaum Associates Ltd.

Posner, M. I., Nissen, M., \& Odgen, W. (1978). Attended and unattended processing modes: The role of set for spatial location. In H. L. Pick \& E. Saltzman (Eds.), Modes of perceiving and processing information (pp. 128-181). Hillsdale, NJ: Lawrence Erlbaum Associates, Inc.

Posner, M. I., Rafal, R. D., Choate, L. S., \& Vaughan, J. (1985). Inhibition of return: Neural basis and function. Cognitive Neuropsychology, 2, 211-228.

Posner, M. I., Walker, J. A., Friedrich, F. J., \& Rafal, R. D. (1984). Effects of parietal injury on covert orienting of attention. Journal of Neuroscience, 4, 1863-1874.

Prime, D. J., \& Ward, L. M. (2004). Inhibition of return from stimulus to response. Psychological Science, 15, 272-276. 
Rafal, R., Calabresi, P. A., Brennan, C. W., \&Sciolto, T. K. (1989). Saccade preparation inhibits reorienting to recently attended locations. Journal of Experimental Psychology: Human Perception and Performance, 15, 673-685.

Rafal, R., \& Henik, A. (1994). The neurology of inhibition: Integrating controlled and automatic processes. In D. Dagenbach \& T. H. Carr (Eds.), Inbibitory processes in attention, memory and language (pp. 1-51). San Diego, CA: Academic Press.

Rankins, D., Bradshaw, J., Moss, S., \& GeorgiouKaristianis, N. (2004). Inhibition of return in obsessive-compulsive disorder. Journal of the International Neuropsychological Society, 10, 54-59.

Reuter-Lorenz, P. A., Jha, A. P., \& Rosenquist, J. N. (1996). What is inhibited in inhibition of return? Journal of Experimental Psychology: Human Perception and Performance, 22, 367-378.

Richards, J. E. (2000). Localizing the development of covert attention in infants with scalp event-related potentials. Developmental Psychology, 36, 91-108.

Roelofs, K., van Galen, G. P., Eling, P., Keijsers, G. P. J., \& Hoogduin, C. A. L. (2003). Endogenous and exogenous attention in patients with conversion paresis. Cognitive Neuropsychology, 20, 733-745.

Samuel, A. G., \& Kat, D. (2003). Inhibition of return: A graphical meta-analysis of its time course and an empirical test of its temporal and spatial properties. Psychonomic Bulletin E Review, 10, 897-906.

Sapir, A., Hayes, A., Henik, A., Danziger, S., \& Rafal, R. (2004). Parietal lobe lesions disrupt saccadic remapping of inhibitory location tagging. Journal of Cognitive Neuroscience, 16, 503-509.

Sapir, A., Henik, A., Dobrusin, M., \& Hochman, E. Y. (2001). Attentional asymmetry in schizophrenia: Disengagement and inhibition of return deficits. Neuropsychology, 15, 361-370.

Sapir, A., Rafal, R., \& Henik, A. (2002). Attending to the thalamus: Inhibition of return and nasaltemporal asymmetry in the pulvinar. Neuroreport, 13, 693-697.

Sapir, A., Soroker, N., Berger, A., \& Henik, A. (1999). Inhibition of return in spatial attention: Direct evidence for collicular generation. Nature Neuroscience, 2, 1053-1054.

Schmidt, W. C. (1996). "Inhibition of return" without visual input. Neuropsychologia, 34, 943-952.

Spence, C., Lloyd, D., McGlone, F., Nicholls, M. E., \& Driver, J. (2000). Inhibition of return is supramodal: A demonstration between all possible pairings of vision, touch, and audition. Experimental Brain Research, 134, 42-48.

Sumner, P. (2006). Inhibition vs. attentional momentum in cortical and collicular mechanisms of IOR. Cognitive Neuropsychology, 23, 1035-1048.

Sumner, P., Nachev, P., Vora, N., Husain, M., \& Kennard, C. (2004). Distinct cortical and collicular mechanisms of inhibition of return revealed with $\mathrm{S}$ cone stimuli. Current Biology, 14, 2259-2263.

Takeda, Y., \& Yagi, A. (2000). Inhibitory tagging in visual search can be found if search stimuli remain visible. Perception E Psychophysics, 62, 927-934.

Tassinari, G., Aglioti, S., Chelazzi, L., Marzi, C. A., \& Berlucchi, G. (1987). Distribution in the visual field of the costs of voluntarily allocated attention and of the inhibitory after-effects of covert orienting. Neuropsychologia, 25, 55-71.

Taylor, T. L., \& Klein, R. M. (1998). On the causes and effects of inhibition of return. Psychonomic Bulletin $\xi^{\circ}$ Review, 5, 625-643.

Taylor, T. L., \& Klein, R. M. (2000). Visual and motor effects in inhibition of return. Journal of Experimental Psychology: Human Perception and Performance, 26, 1639-1656.

Tipper, S. P., Driver, J., \& Weaver, B. (1991). Objectcentred inhibition of return of visual attention. Quarterly Journal of Experimental Psychology, 43A, 289-298.

Tipper, S. P., Rafal, R., ReuterLorenz, P. A., Starrveldt, Y., Ro, T., Egly, R., et al. (1997). Object-based facilitation and inhibition from visual orienting in the human split-brain. Journal of Experimental Psychology: Human Perception and Performance, 23, 1522-1532.

Tipper, S. P., Weaver, B., Jerreat, L. M., \& Burak, A. L. (1994). Object-based and environment-based inhibition of return of visual attention. Journal of Experimental Psychology: Human Perception and Performance, 20, 478-499.

Valenza, E., Simion, F., \& Umiltà, C. (1994). Inhibition of return in newborn infants. Infant Behaviour and Development, 17, 293-302.

Vivas, A. B., Humphreys, G. W., \& Fuentes, L. J. (2003). Inhibitory processing following damage to the parietal lobe. Neuropsychologia, 41, 15311540.

Vivas, A. B., Humphreys, G. W., \& Fuentes, L. J. (2006). Abnormal inhibition of return: A review and new data on patients with parietal lobe damage. Cognitive Neuropsychology, 23, 1049-1064. 